CLINICAL STUDY

\title{
Randomized prospective study comparing a single radioiodine dose and a single laser therapy session in autonomously functioning thyroid nodules
}

\author{
Helle Døssing, Finn Noe Bennedbæk ${ }^{1}$, Steen Joop Bonnema ${ }^{2}$, Peter Grupe ${ }^{3}$ and Laszlo Hegedüs ${ }^{2}$ \\ Department of Oto-Rhino-Laryngology and Neck Surgery, Odense University Hospital, DK-5000 Odense C, Denmark, ${ }^{1}$ Department of Endocrinology and \\ Metabolism, Herlev University Hospital, DK-2730 Herlev, Denmark, Departments of ${ }^{2}$ Endocrinology and Metabolism and ${ }^{3}$ Nuclear Medicine, Odense \\ University Hospital, DK-5000 Odense, Denmark \\ (Correspondence should be addressed to H Døssing; Email: helle.doessing@ouh.fyns-amt.dk)
}

\begin{abstract}
Objective: To compare the efficacy of interstitial laser photocoagulation (ILP) with radioiodine in hot thyroid nodules.

Design: Thirty consecutive outpatients with subclinical or mild hyperthyroidism and a scintigraphically solitary hot nodule with extraglandular suppression were randomized to either one ILP session or one radioiodine $\left({ }^{131} \mathrm{I}\right)$ dose.

Methods: ILP was performed under continuous ultrasound-guidance and with an output power of 2.5-3.5 W. ${ }^{131}$ I was given as a single dose based on thyroid volume and a 24 -h thyroid ${ }^{131}$ I uptake. Thyroid function and nodule volume were evaluated at inclusion and at 1,3 and 6 months after treatment.

Results: Normalization of serum TSH was achieved in 7 out of 14 patients in the ILP group and in all 15 patients in the ${ }^{131}$ I group $(P=0.0025)$. In the ILP group, mean thyroid nodule volume reduction was $44 \pm 5 \%$ (s.E.M.; $P<0.001$ ), and in the ${ }^{131}$ I group $47 \pm 8 \%(P<0.001)$, within 6 months, without between-group difference $(P=0.73)$. The mean reduction of total thyroid volume was $7 \pm 5 \%$ in the ILP group $(P=0.20)$ and $26 \pm 8 \%(P=0.006)$ in the ${ }^{131}$ I group $(P=0.06$ between-group). Two patients in the ${ }^{131}$ I group developed hypothyroidism but no major side effects were seen.

Conclusions: This first randomized study, comparing ILP with standard therapy, demonstrates that ILP and ${ }^{131}$ I therapy approximately halves thyroid nodule volume within 6 months; but in contrast to ${ }^{131} \mathrm{I}$, extranodular thyroid volume is unaffected by ILP and no patient developed hypothyroidism. Using the present design, ILP seems inferior to ${ }^{131} \mathrm{I}$ therapy in normalization of serum TSH. The potential value of ILP as a non-surgical alternative to ${ }^{131}$ I needs further investigation.
\end{abstract}

European Journal of Endocrinology 157 95-100

\section{Introduction}

Approximately $10 \%$ of solitary nodules are scintigraphically hot, half of which are autonomously functioning $(1,2)$. Biochemical hyperthyroidism, often subclinical with suppressed serum thyroid-stimulating hormone (TSH) and normal peripheral thyroid hormones, is present in $\sim 75 \%$ of the patients with an autonomously functioning thyroid nodules (AFTN; (2)).

Radioiodine and surgery are both effective in the treatment of pretoxic as well as toxic thyroid nodules (3). The reluctance to use radioactive iodine, especially in southern Europe, has lead to the introduction of ultrasound (US)-guided percutaneous ethanol injection (PEI) of AFTN. Results have been promising, but the limitations of PEI are related to the difficulty in predicting the diffusion of the ethanol which can cause pronounced pain, and side effects such as extraglandular fibrosis impeding subsequent surgery, needed in case of treatment failure. The need of repeated injections to achieve euthyroidism and nodule shrinkage may increase the risk of side effects. This, in addition to the lack of randomized trials testing PEI against standard therapy (surgery or ${ }^{131} \mathrm{I}$ ), has clearly limited the routine use of PEI (1, 4-7).

US-guided percutaneous interstitial laser photocoagulation (ILP) has been introduced in solid cold thyroid nodules (8-11). ILP is a minimally invasive interventional procedure and the necrosis induced by the thermic energy can be delivered in a controlled fashion with no or minimal damage to the surrounding tissue $(12,13)$. The procedure is performed on an outpatient basis and is well tolerated. The nodule volume reduction is comparable to that obtained following one PEI treatment $(4,14)$, and 
the only reported side effects have been slight discomfort and moderate pain for up to a few days $(8,9)$.

The feasibility and the efficacy of US-guided ILP in AFTN has previously been reported only in few patients $(15,16)$, but never in a randomized study comparing it with standard therapy. Therefore, the aim of our study was to evaluate the effect of ILP in a prospective randomized study where ILP was compared with ${ }^{131} \mathrm{I}$ therapy.

\section{Patients and methods}

Thirty consecutive patients with a median thyroid nodule volume of $9.8 \mathrm{ml}$ (range $3.0-43.0 \mathrm{ml}$ ) and a median total thyroid volume of $25.0 \mathrm{ml}(11.0-50.0 \mathrm{ml}$ ), referred due to subclinical or mild hyperthyroidism or a thyroid nodule, were included. All patients had a solitary hot thyroid nodule, evaluated clinically, scintigraphically and by US. The latter demonstrated increased vascularization by colour Doppler. None had prior radiation to the neck or symptoms or findings suggestive of thyroid malignancy (rapidly growing, firm or adherent nodules, compression symptoms or regional lymphadenopathy). Blood tests included serum thyrotrophin (TSH; normal range 0.3-4.0 mU/ml) determined by DELFIA (Wallac OY, Turku, Finland), serum total thyroxine ( $\mathrm{T}_{4} ;$ normal range $65-135 \mathrm{mmol} / \mathrm{l}$ ) determined by RIA (Diagnostic Products Corp., Los Angeles, CA, USA) and serum total triiodothyronine $\left(\mathrm{T}_{3}\right.$; normal range $\left.1.00-2.10 \mathrm{mmol} / \mathrm{l}\right)$ determined by RIA (Johnson \& Johnson, Clinical Diagnostics Ltd, Amersham). Free $\mathrm{T}_{4}\left(\mathrm{FT}_{4}\right)$ and free $\mathrm{T}_{3}\left(\mathrm{FT}_{3}\right)$ indices were calculated multiplying serum $\mathrm{T}_{4}$ and $\mathrm{T}_{3}$ levels respectively, with the percentage $\mathrm{T}_{3}$ resin uptake. Serum anti-thyroid peroxidase antibodies (anti-TPOAb) were determined by RIA DYNO test (Brahms diagnostica GMBH, Berlin, Germany; normal range $<60 \mathrm{U} / \mathrm{ml}$ ).

Randomization was achieved using a random number generator on a computer. The protocol was approved by the ethics committee of the county of Funen (journal no. $20000240)$ and registered at www.clinicaltrials.gov (registration number: NCT00150150). Prior to participation, all the patients gave signed informed consent. Patients were randomized to one treatment session of US-guided ILP or one dose of ${ }^{131}$ I. Both ILP and ${ }^{131} \mathrm{I}$ therapy were carried out on an outpatient basis. One patient in the ILP group was excluded from the study since she was lost to follow-up immediately after treatment, leaving 29 patients for the final analysis. These individuals were investigated with assessment of the thyroid function and nodule volume at 1,3 and 6 months after the treatment. Thyroid function was additionally investigated 2 months after treatment. Furthermore, antiTPOAb was determined and a scintigraphy performed 6 months after treatment. Thyroid nodule volume was calculated on the basis of an ultrasonic scanning procedure, by recording cross-sections through the gland, using a $5.5 \mathrm{MHz}$ static compound scanner (type 1846, B\&K Medical, Gentofte, Denmark) as previously described (17).

In the ILP group, a Logiq 500 US scanner (GE Medical Systems, Milwaukee, WI, USA) with a $12 \mathrm{MHz}$ linear transducer (type 739L) mounted with a needle steering device for precise US-guided punctures was used. Under sterile conditions and guided by US, the laser fibre (0.4 $\mathrm{mm}$ in diameter) was positioned in the thyroid nodule through the lumen of an 18 gauge $(1.2 \mathrm{~mm})$ needle and preceded by local anaesthesia with lidocaine $(10 \mathrm{mg} / \mathrm{ml})$. The needle was withdrawn at least $20 \mathrm{~mm}$ leaving the end of the fibre in direct contact with the tissue. Patients were then treated with an output power of $2.5-3.5 \mathrm{~W}$, depending on pretreatment nodule volume and the position of the nodule. The entire procedure was performed with an infrared diode (model 15; Diomed, Cambridge, England) laser power source and under continuous US-guidance. During laser treatment, the vapour from the tissue was clearly visible on US as an irregular echogenic area enlarging over time. Based on previous experience, at present, we suggest a safety distance from the neurovascular bundle of at least $1.5 \mathrm{~cm}$ to avoid injury to these structures as a result of the thermal effect of $\operatorname{ILP}(8,12)$. Typically, three or four areas were treated and the absence of flow signs in the treated areas, evaluated by colour flow Doppler, was used as a surrogate marker of immediate treatment success, to determine when the procedure should be terminated. The energy delivered during photocoagulation was recorded.

${ }^{131} \mathrm{I}$ was given as a single dose calculated as 3.7 MBq/g total thyroid mass (estimated by planimetric ultrasonography), corrected to a $100 \%$ thyroid uptake of ${ }^{131} \mathrm{I}$ after $24 \mathrm{~h}$. The maximum therapeutic ${ }^{131} \mathrm{I}$ activity was limited to $600 \mathrm{MBq}(16.2 \mathrm{mCi})$ according to the official Danish health authority regulations.

If severe hyperthyroid symptoms developed after the treatment, $\beta$-blockade (propranolol) was offered. Myxoedema, defined as serum TSH above normal levels and free thyroid hormones below normal levels, was treated with levo- $\mathrm{T}_{4}\left(\mathrm{~L}-\mathrm{T}_{4}\right)$.

Treatment outcome was evaluated in relation to complete cure, defined as normalization or elevation of serum TSH at the 6-month evaluation. Transient hypothyroidism was ruled out by reducing the ${\mathrm{L}-\mathrm{T}_{4}}_{4}$ dose before final classification.

\section{Statistical analysis}

Results for continuous data are given as median and ranges or mean and s.E.M. Fisher's exact test, one- and two-way ANOVA, Wilcoxon's-signed ranks test and the Mann-Whitney test were used to compare baseline characteristics and analyse differences in outcome. A P value of $<0.05$ was considered significant. 


\section{Results}

\section{Baseline characteristics}

Clinical data of the patients randomized to ${ }^{131}$ I therapy or ILP treatment are given in Table 1. Baseline characteristics were not significantly different in the two groups. Five patients in each group had mild hyperthyroidism but none needed anti-thyroid medication before therapy. In the five hyperthyroid patients, randomized to laser therapy, median serum TSH was $0.01 \mathrm{mU} / \mathrm{ml}$ (range $<0.001-0.03$ ), median $\mathrm{FT}_{4} \mathrm{I}$ was $145 \mathrm{mmol} / \mathrm{l}$ (range 81-177) and median $\mathrm{FT}_{3} \mathrm{I}$ was $2.7 \mathrm{mmol} / \mathrm{l}$ (range 1.9-4.4). In the five hyperthyroid patients, randomized to ${ }^{131} \mathrm{I}$ therapy, median serum TSH was $<0.01 \mathrm{mU} / \mathrm{ml}$ (range $<0.001-0.03$ ), $\mathrm{FT}_{4} \mathrm{I}$ was $174 \mathrm{mmol} / \mathrm{l}$ (range 143-217) and $\mathrm{FT}_{3} \mathrm{I}$ was $3.8 \mathrm{mmol} / \mathrm{l}$ (range $2.5-4.3$ ). There was no statistically significant difference in serum TSH $(P=0.31), \mathrm{FT}_{4} \mathrm{I}$ $(P=0.51)$ and $\mathrm{FT}_{3} \mathrm{I}(P=0.42)$ between these two subgroups with mild hyperthyroidism (Table 1) .

\section{Outcome: nodule and thyroid volume}

In the ILP group, median total energy given was $1726 \mathrm{~J}$ (range 796-2700), corresponding to a median energy of $217 \mathrm{~J}$ (range 19-553) per millilitre initial nodule volume. The median duration of the ILP treatment was $600 \mathrm{~s}$ (range 411-900). In the ILP group, the mean nodule volume reduction was $44 \pm 5 \%$ (S.E.M.) at 6 months followup $(P<0.001)$ with most of the effect evident during the first 3 months (Fig. 1). Scintigraphy was normalized (homogeneous uptake without any sign of the nodule) in 2 out of 14 patients. The mean reduction in total thyroid volume was $7 \pm 5 \%$ (s.E.M.; $P=0.20$ ) after 6 months (Table 1). In the ${ }^{131}$ I group, the median activity of ${ }^{131}$ I was $327 \mathrm{MBq}$ (range 200-600). In this group, the overall nodule volume reduction was $47 \pm 8 \%$ after 6 months. Most of the effect was evident during the first 3 months (Fig. 1). After ${ }^{131}$ I therapy, the thyroid scintigraphy was normalized in 8 out of 15 patients $(P=0.0025$ compared with ILP). The overall mean reduction in thyroid volume was $26 \pm 8 \%(P=0.006)$ during follow-up. There was no significant between-group difference in the nodule volume reduction $(P=0.73)$, while the difference in the reduction of the total thyroid volume was borderline significant $(P=0.06$ between-groups; Table 1$)$.

\section{Outcome: thyroid function}

At the 6-month investigation, the mean $\mathrm{FT}_{3} \mathrm{I}$ was $2.2 \pm$ $0.2 \mathrm{U} / \mathrm{l}$ (range 2.4-3.3) in the ILP group and $2.3 \pm 0.3 \mathrm{U} / \mathrm{l}$ (range 1.30-5.13) in the ${ }^{131}$ I group $(P=0.76)$. The mean $\mathrm{FT}_{4} \mathrm{I}$ in the ILP group was $109 \pm 7 \mathrm{U} / \mathrm{l}$ (range 66-150) and in the ${ }^{131}$ I group was $127 \pm 14 \mathrm{U} /$ (range $57-270$; $P=0.37$ ). Serum TSH was normalized in 7 out of 14 patients treated with ILP and in all 15 patients treated with ${ }^{131}$ I therapy. In all cases with normalization of serum TSH, this was achieved within 3 months of therapy. Two patients receiving ${ }^{131}$ I developed hypothyroidism 6 months after therapy (one of whom had positive antiTPOAb initially).

\section{Side effects}

In one patient in the ILP group, the laser treatment induced pain, which disappeared momentarily when the energy was turned off. The only post-treatment side effect of ILP was slight to moderate pain in 5 out of 15 patients. Self-reported median duration of pain or tenderness was 2.5 days (range 0-5.0) and alleviation was obtained with mild analgesics.

Table 1 Baseline and treatment characteristics of the two groups with solitary autonomous thyroid nodules.

\begin{tabular}{|c|c|c|c|c|c|c|}
\hline Variable & $\begin{array}{l}\text { Laser therapy: } \\
\text { baseline }(n=14)\end{array}$ & $\begin{array}{c}131 \text { I therapy: } \\
\text { baseline }(n=15)\end{array}$ & $\begin{array}{c}P \\
\text { values }\end{array}$ & $\begin{array}{c}\text { Laser therapy: } 6 \\
\text { months follow-up } \\
(n=14)\end{array}$ & $\begin{array}{l}{ }^{131} \text { I therapy: } 6 \\
\text { months follow- } \\
\text { up }(n=15)\end{array}$ & $P$ values \\
\hline Age (years) & $58 \pm 3$ & $54 \pm 3$ & 0.53 & & & \\
\hline $\operatorname{Sex}(M / F)$ & $3 / 11$ & $2 / 13$ & 0.72 & & & \\
\hline Nodule volume (ml) & $10.6 \pm 2.5$ & $11.2 \pm 1.6$ & 0.35 & $4.6 \pm 0.6$ & $6.3 \pm 1.5$ & 0.69 \\
\hline Nodule volume reduction & & & & $44 \pm 5 \%$ & $47 \pm 8 \%$ & 0.73 \\
\hline Thyroid volume (ml) & $26.2 \pm 3.0$ & $24.6 \pm 1.8$ & 0.96 & $21.5 \pm 2.0$ & $18.4 \pm 2.5$ & 0.19 \\
\hline Thyroid volume reduction & & & & $7 \pm 5 \%$ & $26 \pm 8 \%$ & 0.06 \\
\hline Serum TSH $(\mathrm{mU} / \mathrm{ml})^{\mathrm{a}}$ & $0.03(<0.001-0.20)$ & $0.02(<0.001-0.27)$ & 0.91 & $0.32(<0.001-0.82)$ & $1.21(0.43-2.58)^{\mathrm{b}}$ & 0.02 \\
\hline $\begin{array}{l}\text { Normal/subnormal serum } \\
\text { TSH }(n)\end{array}$ & $0 / 14$ & $0 / 15$ & 0.98 & $7 / 7$ & $15 / 0$ & $<0.01$ \\
\hline $\mathrm{FT}_{4}$ index $(\mathrm{U} / \mathrm{l})^{\mathrm{c}}$ & $113 \pm 9$ & $137 \pm 11$ & 0.17 & $109 \pm 7$ & $127 \pm 14^{b}$ & 0.37 \\
\hline $\mathrm{FT}_{3}$ index $\left(\mathrm{U} / \mathrm{I}^{\mathrm{d}}\right.$ & $2.3 \pm 0.2$ & $2.6 \pm 0.2$ & 0.84 & $2.2 \pm 0.2$ & $2.3 \pm 0.3^{b}$ & 0.76 \\
\hline Anti-TPOAb (pos./neg.) & $0 / 14$ & $2 / 13$ & 0.51 & $0 / \overline{14}$ & $2 / 13$ & 0.51 \\
\hline
\end{tabular}

Values are number of cases, mean \pm S.E.M. or median/range.

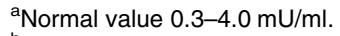

${ }^{\mathrm{b}}$ Two patients who developed hypothyroidism are omitted.

${ }^{\mathrm{C}}$ Normal value $60-140 \mathrm{U} / \mathrm{l}$.

${ }^{\mathrm{d}}$ Normal value $0.95-2.20 \mathrm{U} / \mathrm{l}$. 




Figure 1 Thyroid nodule volume reduction 1, 3 and 6 months after ILP treatment and ${ }^{131}$ I therapy (mean \pm S.E.M). Laser vs. ${ }^{131}$ I at 6 months, $P=0.73$.

After ${ }^{131}$ I therapy, one patient had tenderness of the thyroid gland lasting for few days. Two developed hypothyroidism 6 months after therapy (one of whom had positive anti-TPOAb initially). Finally, hemithyroidectomy (benign histology) was performed in one patient receiving ${ }^{131}$ I because of persistent pressure symptoms during follow-up.

\section{Discussion}

The prevalence of AFTN ranges from $0.9 \%$ of unselected patients in regions with sufficient iodine supply, up to $9 \%$ in iodine-deficient regions $(2,3,5)$. Treatment may be indicated either due to nodule size, compression of adjacent structures, cosmetic complaints, hyperthyroid symptoms, or in order to avoid progression of the hyperthyroidism (annual risk around $4 \%)(1,18)$. Since subclinical hyperthyroidism has a detrimental effect on particularly the skeleton and the cardiovascular system $(19,20)$, treatment is often recommended, especially in elderly patients $(21,22)$. Current standard treatment options for AFTN include ${ }^{131}$ I-therapy and surgery. Many regard ${ }^{131} \mathrm{I}$ as the therapy of choice for patients with AFTN. Treatment with low-dose ${ }^{131}$ I leads to a reduction of the nodule volume by $\sim 45 \%$ within 2 years of therapy. The incidence of hypothyroidism after

${ }^{131}$ I therapy is reported to be $\sim 10 \%$ within 5 years and increases in frequency over time $(1,5,23)$.

Chemical ablation with ethanol injected under US-guidance is not currently adopted by the majority of endocrinologists as repeated injections are needed (3, 24) and clear disadvantages and limitations, especially when treating solid nodules, are related to this technique $(5,25,26)$. The immediate advantage of ILP-induced thermal destruction is that the spread of energy, and thus the extent of tissue destruction, can be controlled, in contrast to the tissue necrosis induced by ethanol $(13,27,28)$. Under US-guidance, the laser fibre is clearly visualized as a hyperechoic spot, and during treatment the areas treated are clearly visualized as hyperechogenic areas enlarging over time. Therefore, the advantage of ILP is the superior precision in inducing a well-defined area of tissue necrosis with a reproducible pattern. So far, the only side effect seems to be slight to moderate pain for a few days (8-10).

Previously, we have demonstrated that the size of scintigraphically cold thyroid nodules was reduced by about $45 \%$ after one ILP treatment $(8,9)$. The technique has also successfully been applied in an 18-year-old woman with an AFTN (15). However, the experience with ILP in AFTN is limited $(16,29)$. Seven patients with an AFTN were treated successfully by Spiezia et al. (29), while Pacella et al. (16) concluded that ILP was not effective in the control of an AFTN. Evidently, both studies involved few patients and were non-randomized. Our study is the first to compare ILP and standard treatment. In order to standardize the comparison of ILP and ${ }^{131}$ I, the laser treatment was given as a single treatment session, but the fibre was relocated in typically three or four areas to affect as much as possible of the nodule tissue. After one ILP session, we achieved a mean nodule volume reduction of $44 \%$, which is comparable with that obtained by ${ }^{131}$ I therapy. Since normalization of the scintigraphy was obtained to a lesser degree after ILP than after ${ }^{131} \mathrm{I}$, despite a similar nodule volume reduction, it seems that the AFTN reacts differently to thermic- and radioactive destruction. Unfortunately, absence of flow signs in the treated areas, as evaluated by colour flow Doppler, can only serve as a rough marker of immediate treatment success following ILP but cannot predict clinical cure. By increasing the energy (up to six ILP-treatment sessions), a mean reduction of up to $61-74 \%$ may be achieved $(16,29)$.

In the present study, thyroid function was normalized defined as normalization of serum TSH - in $47 \%$ of the patients after ILP and in all patients after ${ }^{131} \mathrm{I}$, two of whom developed hypothyroidism. In the ILP group those with mild hyperthyroidism seemed less hyperthyroid (although not significantly so) when compared with the ${ }^{131}$ I group, but nonetheless treatment success was achieved in all in the ${ }^{131} \mathrm{I}$ group, favouring the latter. Furthermore, long-term efficacy has been confirmed for ${ }^{131}$ I and relapse after 6 months in the ILP group cannot be excluded, as reported for PEI, 1-5 years after successful treatment (30). The scintigraphy was normalized in 2 out of 14 patients after ILP treatment and in 8 out of 15 patients after ${ }^{131}$ I therapy. However, the results of the scintigraphy cannot be used as an indicator of complete cure. Even in patients where euthyroidism is achieved after ${ }^{131}$ I therapy, a hot nodule suppressing the uptake in the extranodular tissue is found in $50 \%$ or more of the patients $1-16$ years later $(23,31)$. Favouring ILP, only patients offered ${ }^{131}$ I developed hypothyroidism. This is most likely due to the perinodular uptake of ${ }^{131} \mathrm{I}(23,32)$, whereas ILP is specifically targeted against the nodule. 
Our randomized study substantiates that US-guided ILP is a safe and minimally invasive technique. However, using the present design, ILP seems inferior to ${ }^{131}$ I therapy for normalization of serum TSH in patients with an AFTN. The nodule volume reduction after ILP is similar to that obtained after ${ }^{131}$ I therapy, whereas the extranodular thyroid tissue is unaffected after ILP. Further large-scale studies, including evaluation of patient satisfaction, should address the efficacy of repeat ILP treatment, before ILP may be considered as a useful alternative for patients who are not candidates for surgery or ${ }^{131}$ therapy.

\section{Acknowledgements}

This study was supported economically by the Agnes and Knut Mørk Foundation, the Novo Nordisk Foundation, the A P Møller Relief Foundation and the A J Andersen and Wife Foundation.

\section{References}

1 Hegedüs L. Clinical practice. The thyroid nodule. New England Journal of Medicine 2004351 1764-1771.

2 Burch HB, Shakir F, Fitzsimmons TR, Jaques DP \& Shriver CD. Diagnosis and management of the autonomously functioning thyroid nodule: the Walter Reed Army Medical Center experience, 1975-1996. Thyroid 19988 871-880.

3 Ferrari C, Reschini E \& Paracchi A. Treatment of the autonomous thyroid nodule: a review. European Journal of Endocrinology 1996 $135383-390$.

4 Bennedbæk FN \& Hegedüs L. Percutaneous ethanol injection therapy in benign solitary solid cold thyroid nodules: a randomized trial comparing one injection with three injections. Thyroid 19999 225-233.

5 Hegedüs L, Bonnema SJ \& Bennedbæk FN. Management of simple nodular goiter: current status and future perspectives. Endocrine Reviews 200324 102-132.

6 Lippi F, Ferrari C, Manetti L, Rago T, Santini F, Monzani F, Bellitti P, Papini E, Busnardo B, Angelini F \& Pinchera A. Treatment of solitary autonomous thyroid nodules by percutaneous ethanol injection: results of an Italian multicenter study. The Multicenter Study Group. Journal of Clinical Endocrinology and Metabolism 1996 81 3261-3264.

7 Papini E, Pacella CM \& Verde G. Percutaneous ethanol injection (PEI): what is its role in the treatment of benign thyroid nodules? Thyroid 19955 147-150.

8 Døssing H, Bennedbæk FN, Karstrup S \& Hegedüs L. Benign solitary solid cold thyroid nodules: US-guided interstitial laser photocoagulation - initial experience. Radiology $2002 \mathbf{2 2 5}$ 53-57.

9 Døssing H, Bennedbæk FN \& Hegedüs L. Effect of ultrasoundguided interstitial laser photocoagulation on benign solitary solid cold thyroid nodules - a randomised study. European Journal of Endocrinology 2005152 341-345.

10 Papini E, Guglielmi R, Bizzarri G \& Pacella CM. Ultrasound-guided laser thermal ablation for treatment of benign thyroid nodules. Endocrine Practice $200410276-283$.

11 Cakir B, Topaloglu O, Gul K, Agac T, Aydin C, Dirikoc A, Gumus M, Yazicioglu K, Ersoy RU \& Ugras S. Effects of percutaneous laser ablation treatment in benign solitary thyroid nodules on nodule volume, thyroglobulin and anti-thyroglobulin levels, and cytopathology of nodule in $1 \mathrm{yr}$ follow-up. Journal of Endocrinological Investigation 200629 876-884.
12 Pacella CM, Bizzarri G, Guglielmi R, Anelli V, Bianchini A, Crescenzi A, Pacella S \& Papini E. Thyroid tissue: US-guided percutaneous interstitial laser ablation - a Feasibility Study. Radiology 2000217 673-677.

13 Prapavat V, Roggan A, Walter J, Beuthan J, Klingbeil U \& Muller G. In vitro studies and computer simulations to assess the use of a diode laser $(850 \mathrm{~nm})$ for laser-induced thermotherapy (LITT). Lasers in Surgery and Medicine 199618 22-33.

14 Bennedbæk FN, Nielsen LK \& Hegedüs L. Effect of percutaneous ethanol injection therapy versus suppressive doses of Lthyroxine on benign solitary solid cold thyroid nodules: a randomized trial. Journal of Clinical Endocrinology and Metabolism 199883 830-835.

15 Døssing H, Bennedbæk FN \& Hegedüs L. Ultrasound guided interstitial laser photocoagulation of an autonomous thyroid nodule - the introduction of a novel alternative. Thyroid 200313 885-888.

16 Pacella CM, Bizzarri G, Spiezia S, Bianchini A, Guglielmi R, Crescenzi A, Pacella S, Toscano V \& Papini E. Thyroid tissue: US-guided percutaneous laser thermal ablation. Radiology 2004 232 272-280.

17 Hegedüs L, Perrild H, Poulsen LR, Andersen JR, Holm B, Schnohr P, Jensen G \& Hansen JM. The determination of thyroid volume by ultrasound and its relationship to body weight, age, and sex in normal subjects. Journal of Clinical Endocrinology and Metabolism $1983 \mathbf{5 6} 260-263$.

18 Sandrock D, Olbricht T, Emrich D, Benker G \& Reinwein D. Longterm follow-up in patients with autonomous thyroid adenoma. Acta Endocrinologica 1993128 51-55.

19 Parle JV, Maisonneuve P, Sheppard MC, Boyle P \& Franklyn JA. Prediction of all-cause and cardiovascular mortality in elderly people from one low serum thyrotropin result: a 10-Year Cohort Study. Lancet 2001358 861-865.

20 Toft AD. Clinical practice. Subclinical hyperthyroidism. New England Journal of Medicine 2001345 512-516.

21 Biondi B, Palmieri EA, Klain M, Schlumberger M, Filetti S \& Lombardi G. Subclinical hyperthyroidism: clinical features and treatment options. European Journal of Endocrinology 2005152 $1-9$.

22 Gharib H, Tuttle RM, Baskin HJ, Fish LH, Singer PA \& McDermott MT. Subclinical thyroid dysfunction: a joint statement on management from the American Association of Clinical Endocrinologists, the American Thyroid Association, and the Endocrine Society. Journal of Clinical Endocrinology and Metabolism 200590 581-585.

23 Nygaard B, Hegedus L, Nielsen KG, Ulriksen P \& Hansen JM. Longterm effect of radioactive iodine on thyroid function and size in patients with solitary autonomously functioning toxic thyroid nodules. Clinical Endocrinology 199950 197-202.

24 Tarantino L, Giorgio A, Mariniello N, de Stefano G, Perrotta A, Aloisio V, Tamasi S, Forestieri MC, Esposito F, Esposito F, Finizia L \& Voza A. Percutaneous ethanol injection of large autonomous hyperfunctioning thyroid nodules. Radiology 2000 214 143-148.

25 Di Lelio A, Rivolta M, Casati M \& Capra M. Treatment of autonomous thyroid nodules: value of percutaneous ethanol injection. American Journal of Roentgenology 1995 $164207-213$.

26 Zingrillo M, Collura D, Ghiggi MR, Nirchio V \& Trischitta V. Treatment of large cold benign thyroid nodules not eligible for surgery with percutaneous ethanol injection. Journal of Clinical Endocrinology and Metabolism 199883 3905-3907.

27 Esnault O, Franc B, Monteil JP \& Chapelon JY. High-intensity focused ultrasound for localized thyroid-tissue ablation: Preliminary Experimental Animal Study. Thyroid 200414 1072-1076.

28 Sanden H \& Hauptmann G. Laser application for minimal invasive reduction of thyroid gland tissue. European Journal of Medical Reserch 19972 527-534. 
29 Spiezia S, Vitale G, Di Somma C, Assanti AP, Ciccarelli A, Lombardi G \& Colao A. Ultrasound-guided laser thermal ablation in the treatment of autonomous hyperfunctioning thyroid nodules and compressive nontoxic nodular goiter. Thyroid 200313 941-947.

30 Monzani F, Caraccio N, Goletti O, Casolaro A, Lippolis PV, Cavina E \& Miccoli P. Treatment of hyperfunctioning thyroid nodules with percutaneous ethanol injection: eight years' experience. Experimental and Clinical Endocrinology and Diabetes 1998 106 54-58.

31 Nygaard B. Changes in the thyroid technetium-99m scintigram after antithyroid and subsequent radioiodine treatment for solitary autonomous nodules. Thyroid 19988 223-227.
32 Hegedüs L, Veiergang D, Karstrup S \& Hansen JM. Compensated 131I-therapy of solitary autonomous thyroid nodules: effect on thyroid size and early hypothyroidism. Acta Endocrinologica 1986 $113226-232$.

Received 13 February 2007

Accepted 16 April 2007 